\title{
Inheritance of Early Maturity in Some Cowpea (Vigna unguiculata (L.) Walp.) Genotypes under Rain Fed Conditions in Northern Ghana
}

\author{
Emmanuel Yaw Owusu (D), ${ }^{1}$ Richard Akromah, ${ }^{2}$ Nicholas Ninju Denwar, ${ }^{1}$ \\ Joseph Adjebeng-Danquah ${ }^{D},{ }^{1}$ Francis Kusi, ${ }^{1}$ and Mohammed Haruna ${ }^{1}$ \\ ${ }^{1}$ CSIR-Savanna Agricultural Research Institute, P.O. Box TL 52, Tamale, Ghana \\ ${ }^{2}$ Kwame Nkrumah University of Science and Technology, Kumasi, Ghana
}

Correspondence should be addressed to Emmanuel Yaw Owusu; owusuemmagh@yahoo.com

Received 2 September 2017; Revised 29 December 2017; Accepted 17 January 2018; Published 28 March 2018

Academic Editor: Christos Tsadilas

Copyright @ 2018 Emmanuel Yaw Owusu et al. This is an open access article distributed under the Creative Commons Attribution License, which permits unrestricted use, distribution, and reproduction in any medium, provided the original work is properly cited.

A field experiment was conducted at Savanna Agricultural Research Institute in 2015 cropping season to examine the inheritance of early maturity among an extra-early maturing landrace Sanzi and a medium maturing variety Padi-Tuya and their progenies. The results indicated highly significant $(P<0.01)$ genetic variations for the maturity indices, namely, days to first flower initiation (DFFI), days to $50 \%$ flowering (DFF), days to first pod maturity (DFPM), days to $90 \%$ pod maturity (DNPM), and plant height (P_PLT), seed per pod (S_Pod), and hundred seed weight (H_SWT). Heritability estimates for these traits varied from $74 \%$ to $99 \%$. No significant differences $(P>0.05)$ were observed between $\mathrm{F}_{1}$ and $\mathrm{RF}_{1}$, implying absence of maternal effect. The segregation ratio in the $F_{2}$ population for early and medium maturity fitted into the ratio $3: 1$, indicating single dominant gene mode of inheritance. Significant positive correlations were found between DNPM, DFFI, DFF, and DFPM; hence selection criteria to improve early maturity of cowpea should focus on these traits. Grain yield also had significant positive correlations with maturity indices indicating high grain yield is associated with late maturity; therefore, high grain yield should be considered alongside early maturity when selecting progenies for earliness.

\section{Introduction}

Cowpea (Vigna unguiculata (L.) Walp.) is one of the most important and native grain legume crops in sub-Saharan Africa (SSA), which accounts for $64 \%$ of the world production $[1,2]$. It is predominantly cultivated by resource limited small holder farmers usually women with average farm size of $0.5-1$ ha $[3,4]$. Cowpea grain $(23-25 \%)$ and leaves $(27-34 \%)$ contain valuable amounts of protein and constitute an important protein source in human diets $[5,6]$. The grain also contains $1.8 \%$ fat and $60.3 \%$ carbohydrates and a rich source of calcium and iron [6]. The dry haulms of cowpea are used as fodder for livestock particularly during the dry season when animal feed is scarce. The dropping from the livestock is also used to improve soil fertility, making the crop an essential and integral part of sustainable crop-livestock farming systems in SSA $[7,8]$. Cowpea can derive up to
99\% of its $\mathrm{N}$ nutrition from symbiotic fixation [9] and fix substantial amounts of symbiotic $\mathrm{N}$ [10]. In fact, cowpea has been shown to contribute about $240 \mathrm{~kg} \mathrm{~N} / \mathrm{ha}$, with $\mathrm{N}$ benefit of $60-70 \mathrm{~kg} / \mathrm{ha}$ to succeeding crops in rotation in unfertile soils [11].

Cowpea production is constrained by several biotic and a biotic stress factors. Among the abiotic factors, terminal drought which usually occurs during flowering and pod filling stage of the crop could cause as high as $80 \%$ yield loss [12]. Climate variability has made the onset and termination of rains unpredictable resulting in a shift to the cultivation of early maturing varieties by farmers [13]. These early maturing varieties are considered climate smart cultivars since they have the ability to escape terminal drought as well as pests and diseases damage that normally occur later in the cropping season [14]. The concept of early maturity in cowpea is a combination of early flower initiation and 
short grain filling period [15]. Early maturity constitutes an important adaptation in agroecological zones with short growing seasons particularly in the arid and semiarid tropics where cowpea genotypes that mature between 55 and 60 days are ideal for cultivation [16, 17]. They provide first food sooner than any other crop, thus shortening the hunger period [18]. Early maturing varieties provide additional seed for the main season cropping and are also suitable for rotation with cereals [19]. Reducing crop cycle has helped to avoid terminal drought, incidence of pests and diseases, and unfavorable temperatures during flowering and podding stages [20]. However, most of the early maturing genotypes such as Sanzi and Sumbirizie which are cultivated by farmers are landraces with either low yields, small grain size, or mottled or brown seed coat colour which are not preferred by consumers. Besides, very few improved cowpea cultivars possessing this trait of earliness are available for cultivation in northern Ghana. There is therefore the need to incorporate the trait with other famer preferred traits to fill the gap.

Genetic variation and the heritability of that trait are among the key considerations for genetic improvement of crops for any trait $[21,22]$. Heritability which is the ability to pass a trait from one generation to the other can be either broad sense (the ratio of the total genetic variance, $\sigma_{G}^{2}$, to total phenotypic variance, $\sigma^{2}{ }_{P}$ ) or narrow sense (the ratio of additive genetic variance, $\sigma^{2}{ }_{\mathrm{A}}$, to the total phenotypic variance, $\boldsymbol{\sigma}_{\mathrm{p}}^{2}$ ) [23]. Heritability estimates help to understand the genetic bases and the extent to which crop improvement can be achieved through selection [21]. Whereas several studies and progress have been made in understanding the heritability of grain yield and quality of cowpea, little progress has been made on the heritability estimates for early maturity and its related traits [23]. Therefore, heritability estimates for maturity in cowpea can be exploited to provide understanding in the genetic basis of early maturity in the development of cowpea varieties that can be cultivated in the changing climate of the northern Ghana. The objectives of this study were to (i) estimate the heritability of maturity indices in some cowpea genotypes, (ii) determine the type of gene action influencing the inheritance of earliness in cowpea, (iii) determine the contribution of maternal effects on inheritance of early maturity in cowpea, and (iv) determine interrelationships among the maturity indices, yield, and yield components.

\section{Materials and Methods}

2.1. Location of the Experiment. The study was conducted at the research fields of the CSIR-Savanna Agricultural Research Institute, Nyankpala. SARI is in the Guinea Savanna agroecological zone of Ghana, located on latitude $9^{\circ}, 25^{\prime}, 41 \mathrm{~N}$, longitude $0^{\circ}, 58^{\prime}, 42 \mathrm{~W}$, and about $183 \mathrm{~m}$ above sea level. The rainfall which normally begins mid-May and ends in early October is unimodal with an average annual rainfall of about $1200 \mathrm{~mm}$ [24]. The cropping season begins with the onset of the rains and commences in mid-June and ends in October with the rest of the season being dry and hazy. The mean annual temperature is recorded to be $27.3^{\circ} \mathrm{C}$ with the hottest part of the season occurring between March and May [24].
The soil is well drained Nyankpala series classified by FAO as Ferric Luvisol. It is brown, fine sandy loam, with low organic matter.

2.2. Plant Materials. Two cultivated varieties Padi-Tuya, medium maturing elite cultivar which matures between 70 and 75 days after planting (DAP) and Sanzi, and extra-early maturing landrace with maturity period of 45-50 DAP were hybridized to generate the segregating populations. Both direct and reciprocal crosses were made. Eight experimental materials including $\mathrm{F}_{1}, \mathrm{RF}_{1}, \mathrm{~F}_{2}, \mathrm{RF}_{2}, \mathrm{BC}_{1}, \mathrm{RBC}_{1}, \mathrm{BC}_{2}$, and $\mathrm{RBC}_{2}$ were developed from the above cross.

2.3. Experimental Procedure. Three experiments were conducted between May 2014 and June 2015. The parents were planted in pots and direct and reciprocal crosses made to produce enough hybrid seeds. Some of the hybrid seeds and their parents were planted. The parents were then backcrossed to the $F_{1} s$ and $R_{1} s$ plants to generate $B_{1}$, $\mathrm{RBC}_{1}, \mathrm{BC}_{2}$, and $\mathrm{RBC}_{2}$ populations. Some of the $\mathrm{F}_{1}$ and $\mathrm{RF}_{1}$ plants were allowed to produce $\mathrm{F}_{2}$ and $\mathrm{RF}_{2}$ seeds, respectively, by themselves. In the third experiment, the eight developed populations together with their parents were evaluated under rain fed condition between March 2015 and May 2015.

2.4. Experimental Design. The experimental materials were arranged in a randomized complete block design (RCBD) with three replications. The sample size (number of plants studied) varied as follows: 30 plants for $\mathrm{P}_{1}, \mathrm{P}_{2}, \mathrm{~F}_{1}$, and $\mathrm{RF}_{1}$ generations, 90 plants for the $\mathrm{BC}_{1}, \mathrm{BC}_{2}, \mathrm{RBC}_{1}$, and $\mathrm{RBC}_{2}$ generations, and 300 plants for each of the $\mathrm{F}_{2}$ and $\mathrm{RF}_{2}$ generations. The plot size comprised one row each for nonsegregating populations $\left(\mathrm{P}_{1}, \mathrm{P}_{2}, \mathrm{~F}_{1}\right.$, and $\left.\mathrm{RF}_{1}\right)$, three rows each for $\mathrm{BC}_{1}, \mathrm{BC}_{2}, \mathrm{RBC}_{1}$, and $\mathrm{RBC}_{2}$ generations, and 10 rows each for $\mathrm{F}_{2}$ and $\mathrm{RF}_{2}$ generations. Each row (constituting 10 plants) was $2.7 \mathrm{~m}$ long with row spacing of $100 \mathrm{~cm}$ and a distance of $30 \mathrm{~cm}$ between plants. One seed was planted per hill; refilling was done immediately after emergence. Field pests were controlled using K-Optimal (Cyhalothrin $15 \mathrm{~g} / \mathrm{l}+$ Acetamiprid 20; EC) at the rate of $500 \mathrm{ml}$ per ha at vegetative stage, flowering, and podding. Weeds were manually controlled as and when necessary.

2.5. Data Collected. Data were collected on maturity indices, namely, number of days to first flower initiation (DFFI), as number from day of planting to the day each plant on each plot flowered, number of days to $50 \%$ flowering (DFF) from day of planting to the day $50 \%$ of the plants on each plot flowered, and number of days to first pod maturity (DFPM) were determined from the day of planting to complete yellowing of first pods on each plant and the number of days to $90 \%$ pod maturity (DNDM) was determined from the day of planting to $90 \%$ yellowing of pods on each plot. Plant height at flowering ( $\mathrm{H} @ \mathrm{~F})$ was measured from the base of each plant to the last terminal bud on the main stem at flowering; plant height at maturity $(\mathrm{H} @ M)$ was also measured from the base of each plant to the last terminal bud on the main stem at pod maturity; canopy width $(\mathrm{CW})$ was measured as an average of the shortest and the longest canopy 
width of each plant. While yield components such as number of pods per plant (N_PLT) were counted, number of seeds per pod (N_SPOD), 10 pods, were randomly selected from each plant and the number of seeds was counted; 100 -seed weight (H_WT) was determined in grams from the weight of 100 randomly selected dried seeds and grain yield per plant (G_YD) was determined as average weight of seeds harvested from each plant.

2.6. Statistical Analyses. Data for all the measured variables were subjected to analyses of variance (ANOVA) using Genstat version 12 [25]. Pearson correlation analysis was also performed to determine the association among the different maturity indices. Treatment means were separated using standard error of difference (SED)

2.7. Heritability Estimates. The following traits DFFI, DFF, DFPM, and DNPM were taken on individual plants and the variances calculated using Genstat version 12 [25]. Variance components (additive, dominance, environment, genetic, and phenotypic) were estimated as described by [26, 27], using the following equations:

$$
\begin{aligned}
& \sigma_{\mathrm{A}}^{2}=2_{\mathrm{F}_{2}}-\left(\boldsymbol{\sigma}_{\mathrm{B} 1}^{2}+\boldsymbol{\sigma}_{\mathrm{B} 2}^{2}\right) \\
& \boldsymbol{\sigma}_{\mathrm{D}}^{2}=\frac{\left[\left(\boldsymbol{\sigma}_{\mathrm{B} 1}^{2}+\boldsymbol{\sigma}_{\mathrm{B} 2}^{2}\right)-\mathrm{F}_{2}-\left(\boldsymbol{\sigma}_{\mathrm{P} 1}^{2}+\boldsymbol{\sigma}_{\mathrm{P} 2}^{2}+\mathrm{F}_{1}\right)\right]}{3} \\
& \boldsymbol{\sigma}_{\mathrm{E}}^{2}=\frac{\left[\boldsymbol{\sigma}_{\mathrm{P} 1}^{2}+\boldsymbol{\sigma}_{\mathrm{P} 2}^{2}+\boldsymbol{\sigma}_{\mathrm{F}_{1}}^{2}\right]}{3} \\
& \boldsymbol{\sigma}_{\mathrm{G}}^{2}=\boldsymbol{\sigma}_{\mathrm{A}}^{2}+\boldsymbol{\sigma}_{\mathrm{D}}^{2} \\
& \boldsymbol{\sigma}_{\mathrm{P}}^{2}=\left(\boldsymbol{\sigma}_{\mathrm{F}_{2}}^{2}\right)=\boldsymbol{\sigma}_{\mathrm{G}}^{2}+\boldsymbol{\sigma}_{\mathrm{E}}^{2}+\boldsymbol{\sigma}_{\mathrm{GE}}^{2},
\end{aligned}
$$

where $\boldsymbol{\sigma}_{\mathrm{A}}^{2}$ is additive variance, $\boldsymbol{\sigma}^{2}$ is dominance variance, $\boldsymbol{\sigma}^{2}{ }_{\mathrm{E}}$ is environmental variance, $\boldsymbol{\sigma}_{{ }_{G}}{ }^{2}$ is genotypic variance, $\boldsymbol{\sigma}^{2}{ }_{P}$ is phenotypic variance, $\boldsymbol{\sigma}^{2} \mathrm{~F}_{1}$ is variance of $\mathrm{F}_{1}, \boldsymbol{\sigma}^{2}{ }_{\mathrm{F}_{2}}$ is variance of $\mathrm{F}_{2}, \boldsymbol{\sigma}_{\mathrm{B} 1}^{2}$ is variance of $\mathrm{BC}_{1}, \boldsymbol{\sigma}_{\mathrm{B} 2}^{2}$ is variance of $\mathrm{BC}_{2}, \boldsymbol{\sigma}_{\mathrm{P} 1}^{2}$ is variance of parent $1, \sigma_{\mathrm{P} 2}^{2}$ is variance of parent 2 .

$$
\begin{aligned}
& \text { Broad sense heritability }\left(\mathrm{H}^{2}{ }_{\mathrm{b}}\right)=\boldsymbol{\sigma}_{\mathrm{G}_{\mathrm{G}}} / \boldsymbol{\sigma}_{\mathbf{P}}^{2} \text {, } \\
& \text { Narrow sense heritability }\left(\mathrm{h}^{2} \mathrm{n}\right)=\boldsymbol{\sigma}_{\mathrm{A}}^{2} \boldsymbol{\sigma}_{\mathbf{P}_{\mathbf{P}}}^{2}[26] \text {. }
\end{aligned}
$$

2.8. Estimation of Maternal Effects. The maternal effect was investigated by comparing the mean values of $F_{1}$ with the mean values of $\mathrm{RF}_{1}$ using a mean-difference test at $5 \%$ level of significance [28].

2.9. Estimation of Inheritance Pattern in Maturity. Chi-square test of significance was used to investigate gene interactions for the $\mathrm{F}_{2}$ generations. The segregation ratios were analyzed using the $\chi^{2}$ value which was obtained from the following formula:

$$
\chi^{2}=\sum \frac{(\text { Observed }- \text { Expected })^{2}}{\text { Expected }}
$$

In addition, maturity indices such as days to flower first initiation (DFFI) and days to first pod maturity (DFPM) were subjected to frequency distribution analysis to elucidate the inheritance pattern in $\mathrm{P}_{1}, \mathrm{P}_{2}, \mathrm{~F}_{1}, \mathrm{~F}_{2}$, and $\mathrm{BC}_{1}$ populations in early and medium maturity classes. Data on DFFI was grouped adopting a descriptor developed by the present authors. Data was scored by observing all the plants in each plot in the three replications. Plants which took less than 44 days to develop their first flower (DFFI $\leq 44$ days) were considered early maturing while those that developed their flowers later ( $>45$ days) were considered medium maturing. On the other hand, plants whose first pod matured in less than 55 days (DFPM $\leq$ 55 days) were considered early maturing and those that matured later (DFPM > 55 days) were recorded as medium maturing, considering the fact that earlier reports classify cowpea genotypes that matured after 80 days as late maturing [29].

\section{Results}

3.1. Performance of Genotypes. Analysis of variance showed highly significant $(P<0.001)$ differences between the parents and different generations $\left(\mathrm{F}_{1}, \mathrm{RF}_{1}, \mathrm{~F}_{2}, \mathrm{RF}_{2}, \mathrm{BC}_{1}, \mathrm{RBC1}, \mathrm{BC}_{2}\right.$, and $\mathrm{RBC}_{2}$ ) for DFFI, DFF, DFPM, DNDM, H@F, H@M, CW, N_PLT, N_SPOD, H_WT, and G_YD (Table 1). However, no significant $(P>0.05)$ differences were observed between the $\mathrm{F}_{1}$ and the $\mathrm{RF}_{1}$ generations for all the traits. The average number of days to first flower initiation (DFFI) ranged from 29.16 to 41.37 days while days to $50 \%$ flowering (DFF) ranged between 33.11 and 44.29 days. Sanzi took the lowest number of days to reach DFFI (29.16) and DFF (33.11) while PadiTuya took the highest number of days to reach DFFI (41.37 days) and DFF (44.29 days). The $F_{1}$ plants took 32.12 and 36.48 days to reach DFFI and DFF, respectively, while the $\mathrm{F}_{2}$ plants took 39.75 and 43.50 days. On the other hand the earlier maturing parent Sanzi had an average of 43.73 days for DFPM and 49.33 days for DNPM but the late maturing parent had 63.53 days for (DFPM) and 70.67 days for (DNPM). Also the $\mathrm{F}_{1}$ plants took an average of 51.56 and 55 days to reach DFPM and DNPM, respectively, while the $\mathrm{F}_{2}$ plants took 55.70 days and 68.33 days for DFPM and DNPM, respectively. Highly significant $(P<0.001)$ genotypic differences were also observed for the average number of days to first pod maturity and $90 \%$ pod maturity with the exception of the following generations: $\mathrm{F}_{1}$ and $\mathrm{RF}_{1}, \mathrm{BC}_{1}$ and $\mathrm{BC}_{2}, \mathrm{RBC}_{1}$ and $\mathrm{RBC}_{2}$, and $\mathrm{F}_{2}$ and $\mathrm{RF}_{2}$. Sanzi took significantly less number of days to reach $90 \%$ pod maturity (49.33 DAP) compared with PadiTuya (70.67 DAP).

Grain yield and yield components showed highly significant $(P<0.001)$ differences among all genotypes studied (Table 1 ). $\mathrm{F}_{1}$ had the highest mean grain yield of $3.16 \mathrm{t} / \mathrm{ha}$ while Sanzi yielded $0.52 \mathrm{t} / \mathrm{ha}$. Mean number of pods per plant ranged from $21.82\left(\mathrm{~F}_{2}\right)$ to $42.56\left(\mathrm{BC}_{2}\right)$. The $\mathrm{F}_{1}$ genotype had the highest mean number of seeds per pod of 17.79 and PadiTuya had the least (15.23). The highest hundred-seed weight of $23.00 \mathrm{~g}$ was recorded for Padi-Tuya compared with $8.91 \mathrm{~g}$ for Sanzi. 


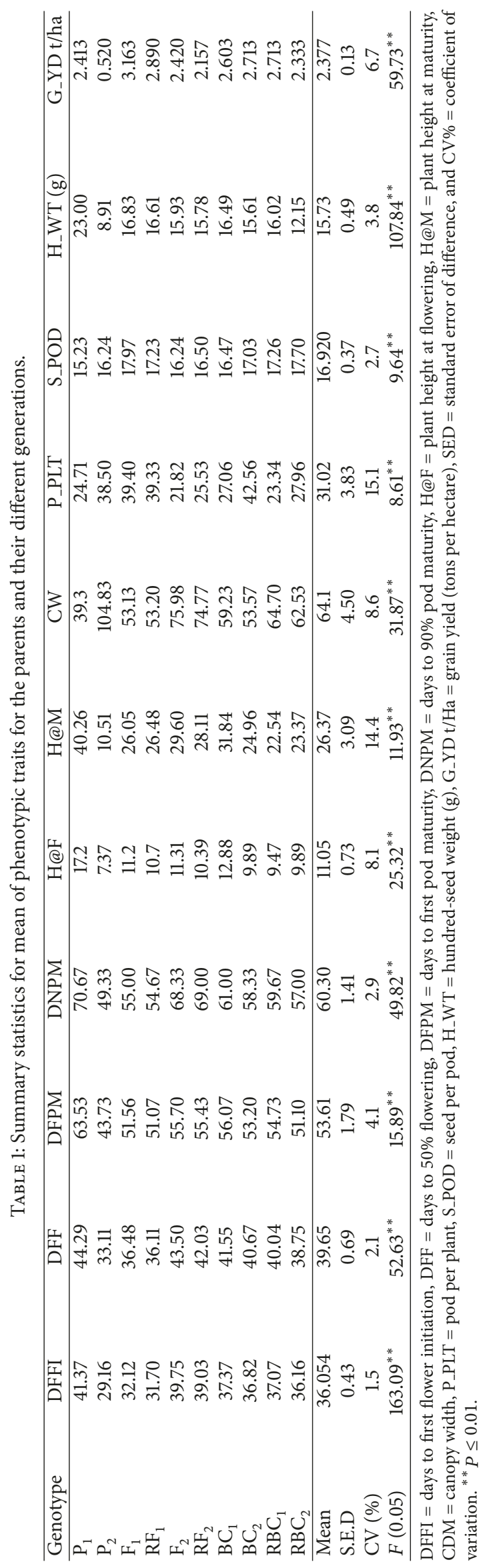


TABLE 2: Estimates of heritability based on variances of DFFI, DFF, DFPM, and DNPM.

\begin{tabular}{lccccccc}
\hline \multirow{2}{*}{ Parameter } & \multicolumn{3}{c}{ Variance components } & \multicolumn{3}{c}{ Heritability estimates } \\
& $\sigma_{p}^{2}$ & $\sigma_{g}^{2}$ & $\sigma_{a}^{2}$ & $\sigma_{d}^{2}$ & $\sigma_{e}^{2}$ & $\mathrm{H}^{2} \mathrm{~b}$ & 89.7 \\
\hline DFFI & 44.88 & 40.24 & 38.68 & 1.56 & 4.64 & 82.2 \\
DFF & 4.89 & 4.84 & 4.84 & $-1.95(0)$ & 1.96 & 99 & 99 \\
DFPM & 69.63 & 51.90 & 51.24 & 0.66 & 17.73 & 74.5 & 73.6 \\
DNPM & 7.65 & 7.01 & 7.03 & $-2.27(0)$ & 2.92 & 91.6 & 91.6 \\
\hline
\end{tabular}

$\mathrm{DFFI}=$ days to first flower initiation, $\mathrm{DFF}=$ days to $50 \%$ flowering, $\mathrm{DFPM}=$ days to first pod maturity, DNPM $=$ days to $90 \%$ pod maturity, $\mathrm{df}=$ degrees of freedom, $\sigma_{p}^{2}=$ phenotypic variance, $\sigma_{g}^{2}=$ genotypic variance, $\sigma_{a}^{2}=$ additive variance, $\sigma^{2}{ }_{d}=$ dominance variance, $\sigma^{2}{ }_{e}=$ environmental variance, $\mathrm{H}^{2} \mathrm{~b}=$ broad sense heritability, and $\mathrm{h}^{2} \mathrm{n}=$ narrow sense heritability.

TABLE 3: Segregation pattern for maturity indices in $\mathrm{F}_{2}$ and $\mathrm{BC}_{1}$ populations.

\begin{tabular}{lcccccccc}
\hline & \multicolumn{9}{c}{ Early } & \multicolumn{2}{c}{ Medium } & & $\chi^{2}(\mathrm{cal})$ & $\chi^{2}\left(\mathrm{Tab}_{0.05,1 \mathrm{df}}\right)$ \\
\hline DFFI & & Observe & Expected & Observe & Expected & 75 & $3: 1$ & 0.27 \\
DFPM & $\mathrm{F}_{2}$ & 221 & 225 & 79 & 75 & $3: 1$ & 0.20 & 3.84 \\
DFFI & $\mathrm{F}_{2}$ & 228 & 225 & 72 & 14 & 22.5 & $3: 1$ & 1.03 \\
DFPM & $\mathrm{BC}_{1}$ & 76 & 67.5 & 67.5 & 26 & 22.5 & $3: 1$ & 0.43 \\
\hline
\end{tabular}

3.2. Maternal Effects. The analysis of variance indicated that there was no significant difference $(P>0.05)$ between the mean values of $\mathrm{F}_{1}$ and $\mathrm{RF}_{1}$ for number of days to $50 \%$ flowering, number of days to first flower initiation, number of days to $90 \%$ pod maturity, number of days to first pod maturity, plant height at maturity $(\mathrm{cm})$, number of pods per plant, hundred-seed weight $(\mathrm{g})$, and grain yield (t/ha) (Table 1).

3.3. Estimates of Variance Components and Heritability. Phenotypic variances ranged from the minimum of 4.89 average number of days to 69.63 for days to first flower initiation (DFFI) and number of days to first pod maturity (DFPM), respectively. Genotypic variances on the other hand varied from 4.84 (DFF) to 51.90 (DFPM). Environmental variance ranged between 1.96 and 17.73 for DFF and DFPM, respectively, while additive variance ranged from 4.84 (DFF) to 51.24 (DFPM), respectively. Dominance variances also ranged from 1.95 (0) to 1.56 for DFF and DFFI, respectively. Estimated heritability values were very high and varied slightly between parameters studied. Broad-sense heritability $\left(\mathrm{H}^{2} \mathrm{~b}\right)$ ranged from 74.50 to $99 \%$, for DFFI, DFF, DFPM, and DNPM, while the narrow-sense heritability $\left(h^{2} n\right)$ varied from $73.60 \%$ to $99 \%$ (Table 2 ).

3.4. The Inheritance Pattern of Maturity in $F_{2}$ Population. Segregation ratios, chi-square, and $P$ values for number of days to first flower initiation and number of days to first pod maturity in the $\mathrm{F}_{2}$ and the $\mathrm{BC}_{1}$ generation are presented in Table 3. The phenotypic ratio, $3: 1$, was used to test for goodness of fit of the observed segregation at $\mathrm{F}_{2}$ and $\mathrm{BC}_{1}$ generations using the chi-square test. Calculated chi-square values $\left(\chi^{2}\right)$ were less than the $P$ values.

Days to first flower initiation varied between minimum of 30 days to maximum of 55 days and DNPM had minimum of 45 days to maximum of 68 days among the $\mathrm{F}_{2}$ population evaluated. In the $\mathrm{BC}_{1}$ generation, the maturity indices ranged between minimum of 31 days and 45 days and maximum of 46 days and 62 days for DFFI and DNPM, respectively (Figure 1). The maturity of the $\mathrm{F}_{1}$ population varied from 30 days to 35 days for DFFI and from 48 days to 56 days for DFPM. The two parents, $\mathrm{P}_{1}$ (38-44 days) and $\mathrm{P}_{2}$ (28-32 days), also differed in their days to first flower initiation (DFFI) as shown in Figure 2. In addition, $\mathrm{P}_{1}$ (58-68 days) also took a longer time to reach pod maturity (DNPM) than $\mathrm{P}_{2}$ which too is between 40 and 47 days to reach DFPM (Figures 2 and $3)$.

3.5. Correlation Analysis. Pearson correlation analysis of maturity, grain yield, and yield-related traits showed significant $(P<0.01)$ correlations among some of the quantitative traits (Table 4). Number of days to $90 \%$ pod maturity had highly significant $(P<0.01)$ positive correlation with mean number days to first flower initiation $(r=0.95)$, number of days to $50 \%$ flowering $(r=0.89)$, and mean number of days to first pod maturity $(r=0.82)$. This trait also recorded a negative relationship with number of pods per plant $(r=-0.65)$ and seed per pod, $(r=-0.46)$. Similarly, highly significant positive correlations were found between grain yield and 100-seed weight $(r=0.61)$, number of pods per plant $(r=0.06)$, and plant height at flower and maturity ( $r=0.36$ and $r=0.45)$, respectively. On the other hand, grain yield was negatively correlated with canopy diameter $(r=-80)$.

\section{Discussion}

Early maturity constitutes an important adaptation in agroecological zones with short growing seasons particularly in the arid and semiarid tropics where such cowpea genotypes which mature between 55 and 60 days are ideal for cultivation $[16,17]$. 

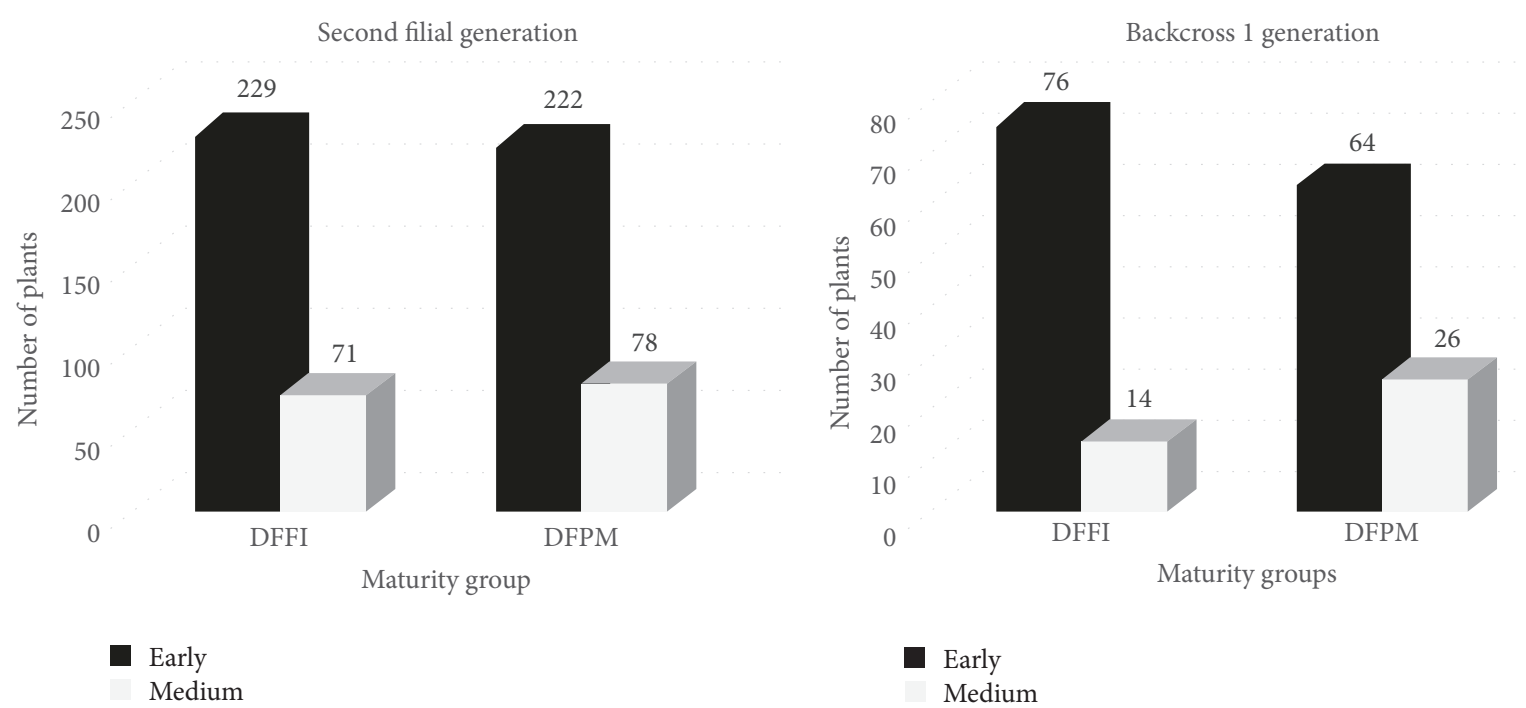

FIGURE 1: Frequency distribution analysis of DFFI and DNPM for $\mathrm{F}_{2}$ and $\mathrm{BC}_{1}$.
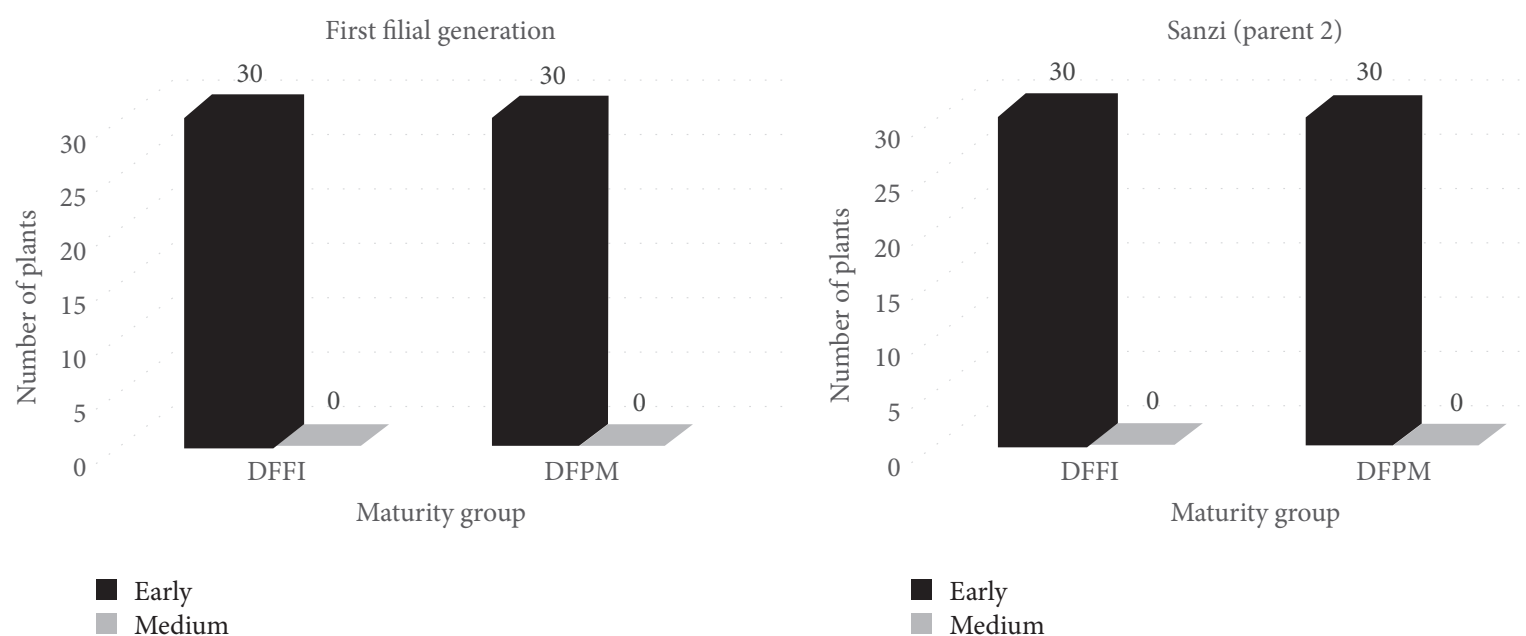

FIgURE 2: Frequency distribution analysis of DFFI and DNPM for $\mathrm{F}_{1}$ and Sanzi.

The highly significant differences in the maturity traits (DFFI, DFF, DFPM, and DNPM) among the parents and their generations indicated a high level of genetic variation. This further implies a large scope for breeding and therefore could provide the necessary genetic information for selection for early maturity in cowpea. The phenotypic difference between the parents and their progeny is very important for genetic inheritance studies, aiming to obtain the precise heritability estimates [30]. Most of the genotypes reached maturity in 60 days. Cowpea varieties which mature in less than 60 DAP are classified as extra-early maturing [29]. The values obtained for number of pods per plant were higher than those reported by Bennet-Lartey and Ofori [30] and Egbe et al. [31] but similar to that of Futuless and Bake [32] for Africa. This resulted from hybrid vigor in most of the genotypes; hence the higher grain yields recorded particularly for $F_{1}$ and $\mathrm{RF}_{1}$ and backcrosses. Hundred-seed weight was relatively higher than the values reported by [33] but similar to those of $[23,30]$. The result from grain yield $(\mathrm{kg} / \mathrm{ha})$ was relatively higher than the values reported by Egbe et al. [31] and similar to those of Alphonsu et al. [34].

The genetic variance components for number of days to first flower initiation and first pod maturity were positive, except for variance due to dominance for number of days to $50 \%$ flowering and that of $90 \%$ pod maturity which were negative values and for practical purposes were considered as zero. Negative values for dominance variances which imply the masking effects of genes were also observed in previous studies using populations of cowpea [35]. The values of genetic variance for all the parameters were greater than those observed for the environmental variance. This suggests that the inheritance of maturity in cowpea is more determined by genetic factors rather than the environment and therefore the trait can be improved through selection $[35,36]$. Mean number of days to first pod maturity had the highest environmental variance of 17.73 , while the mean number of days to first flower initiation was as low as 4.64 , indicating that environmental influence on pod maturity is 
Padi-Tuya (parent 1)

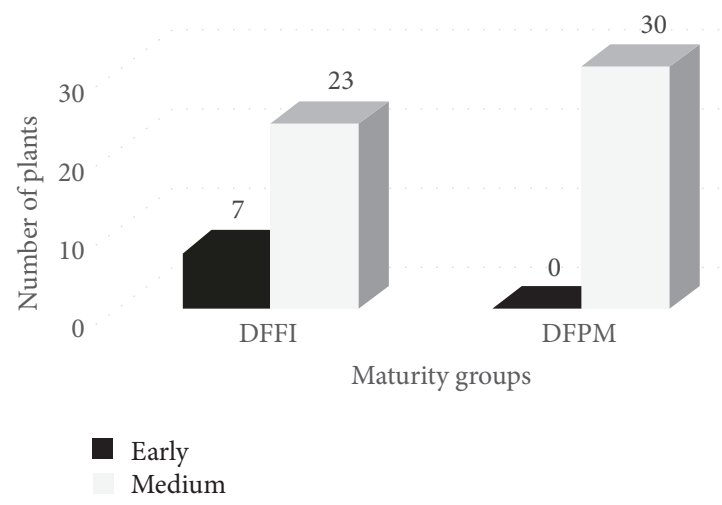

FIGURE 3: Frequency distribution analysis of DFFI and DNPM for Padi-Tuya.

greater than its influence on flowering, because postflowering environmental conditions could have effect of grain filling.

High narrow sense and broad sense heritability estimates observed suggest that the phenotypes of the traits strongly reflect their genotypes [37]. Similar heritability estimates have been reported for days to flowering and days to pod maturity [2]. On the other hand, a high broad sense heritability of $99 \%$ and very low narrow sense heritability estimates of $1.8 \%$ for days to pod maturity and $2.0 \%$ for days to flowering were reported [17]. The insignificant difference between broad and narrow sense heritability estimates could be attributed to negative dominance variance observed [38]. Broad sense heritability in self-pollinating crops is less informative than narrow sense heritability which is a direct measure of additive variance [39]. High heritability estimates of the trait also suggest that high selection pressure could be imposed in any breeding programme aimed at improving early maturity in cowpea [26] resulting in greater genetic gain. This makes it possible to successfully select important traits for improvement in segregating populations [40]. For this reason, selection for early maturity in cowpea could begin in the $\mathrm{F}_{2}$ generation where ample variability is observed. Therefore, marker assisted backcrossing, pedigree, and single-seed descent methods could be very useful in selecting for early maturity in cowpea [41]. High broad and narrow sense heritability estimates for maturity indices also suggest that high selection pressure could be imposed for these traits [42].

The observed segregation frequency in the $\mathrm{F}_{2}$ generation was $3: 1$ for early to medium, respectively. This was significant according to the chi-squares analysis. This implies that inheritance of extra-early maturity in cowpea is under monogenic dominant control. Similar observations were made by Brittingham [43] and Hugo et al. [37]. This indicates that few selection cycles would be necessary to obtain the required accumulation of favourable alleles controlling the inheritance of early maturity in cowpea. Therefore, the development of early maturing cowpea cultivars can be relatively simple through classical breeding strategies such as pedigree and single seed decent.
In addition, the frequency distribution analysis of the $300 \mathrm{~F}_{2}$ plants evaluated also indicated that 229 representing $76.33 \%$ fell within early maturity group while 71 representing $23.66 \%$ were in medium maturity group for DFFI. Similar observation was made for $\mathrm{BC}_{1}$ for the trait. In DFPM, 222 out of the $300 \mathrm{~F}_{2}$ plants representing $74 \%$ were early maturing and the others were medium maturing; $\mathrm{BC}_{1}$ population was not much different from that of $\mathrm{F}_{2}$.

All the $F_{1}$ population were early with means of 32.12 days and 51.56 days for DFFI and DFPM, respectively; these were closer to the early maturing parent (Sanzi), hence elucidation dominant gene effect. About $23 \%$ of the medium parent (Padi-Tuya) fell within the early maturity group for number of days to first flower initiation but could attain the early maturity status for days to first pod maturity. Earliness is determined by the ability a crop to reach flowering and pod filling in a short period [20]. This means that though some plants of Padi-Tuya flowered early, they could not reach early maturity due to long pod filling period required.

The absence in significant differences between the $F_{1}$ and the $\mathrm{RF}_{1}$ populations suggests the absence of maternal effects for inheritance of the maturity indices (DFF, DFFI, DNPM, and DFPM) in cowpea [40]. The inheritance of these parameters could therefore be attributed to nuclear gene control. For that matter any of the parents could be used as a maternal parent in hybridization programme that focuses on the improvement of maturity in cowpea [29].

Correction analysis suggested that grain yield is significant positively correlated with DFF, DFPM, HSWT, and P_PLT, indicating that the longer the genotypes takes to flower and/or mature, the higher the grain yield is. Hundredseed weight was also highly positively correlated with grain yield and DFF and DFPM and DNPM. This implies that longer grain filling period enables bigger grains to be developed and hence high grain yield. Similar observations were made by Nakawuka and Adipala [44]. These observation notwithstanding would be possible to identify individual plants within the segregation population that will combine early maturity with high grain yield. Single seed descent technique could be employed to obtain cowpea genotypes that combine early maturity with high yielding potential [45].

\section{Conclusions}

High heritability estimates for the maturity indices indicate possible transfer of the genes that control early maturity to a medium or late maturing variety. The segregation ratio in the $\mathrm{F}_{2}$ population for early and medium maturity fitted into the ratio, $3: 1$, indicating that maturity in cowpea is conditioned by single dominant gene. Inheritance of early maturity in cowpea is not influenced by maternal effects; hence any of the parents can be used as a maternal parent in hybridization programme for improving early maturity in cowpea. Selection criteria to improve maturity of cowpea should focus on number of days to first flower initiation, number of days to $50 \%$ flowering, and number of days to first pod maturity. Grain yield was positively correlated with DFF, DFPM, HSWT, and P_PLT, indicating that the longer the genotypes takes to flower and/or mature the higher the grain 


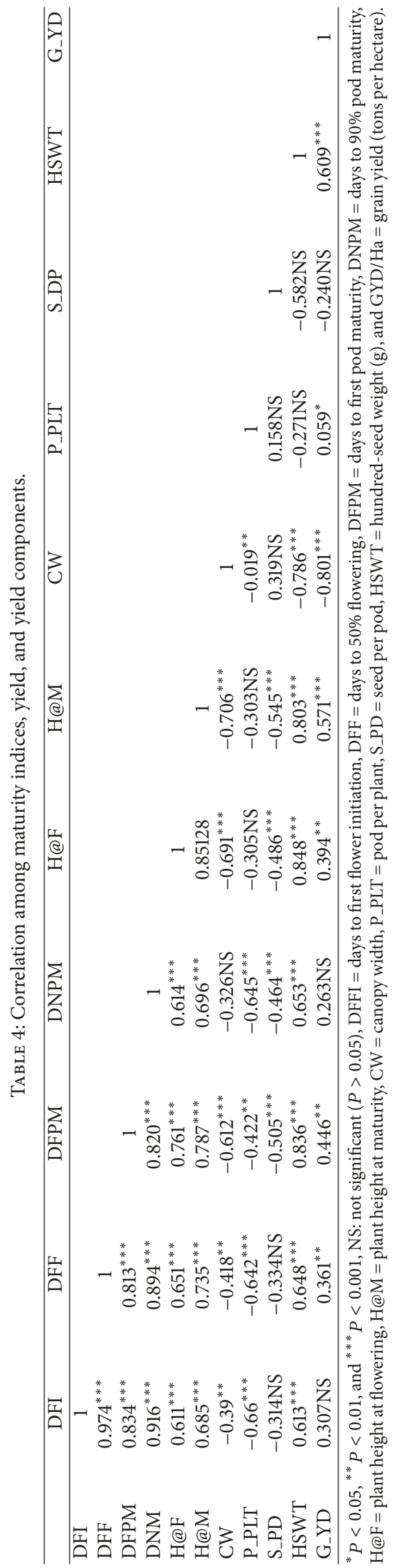


yield is. The study provides understanding of the genetic basis of inheritance of early maturity in cowpea which can be useful in future breeding programmes.

\section{Abbreviations}

$\begin{array}{ll}\mathrm{F}_{1}: & \text { First filial generation } \\ \mathrm{RF}_{1}: & \text { Reciprocal cross of first filial generation } \\ \mathrm{F}_{2}: & \text { Second filial generation } \\ \mathrm{RF}_{2}: & \text { Reciprocal cross of second filial generation } \\ \mathrm{BC}_{1}: & \text { First backcross generation } \\ \mathrm{RBC}_{1}: & \text { First reciprocal backcross generation } \\ \mathrm{BC}_{2}: & \text { Second backcross } \\ \mathrm{RBC}_{2}: & \text { Second reciprocal backcross generation } \\ \text { DFFI: } & \text { Number of days to first flower initiation } \\ \text { DFF: } & \text { Number days to } 50 \% \text { flowering } \\ \text { DFPM: } & \text { Number of days to first pod maturity } \\ \text { DNPM: } & \text { Number of days to } 90 \% \text { maturity } \\ \text { H@M: } & \text { Height at maturity } \\ \text { P_PLT: } & \text { Pod per plant } \\ \text { S_Pod: } & \text { Seed per pod } \\ \text { H_SWT: } & \text { Hundred-seed weight } \\ \text { G_YD: } & \text { Grain yield. }\end{array}$

\section{Conflicts of Interest}

The authors declare that they do not have any conflicts of interest.

\section{Acknowledgments}

The authors are grateful to CSIR-Savanna Agricultural Research Institute and Kwame Nkrumah University of Science and Technology for providing facilities for this experiment. Special thanks and appreciations are due to Dr. S. K. Nutsugah (The Director, CSIR-SARI) for his technical assistance. The efforts of Mr. Emmanuel Kofi Sie for helping in the data collection are well appreciated.

\section{References}

[1] M. P. Timko and B. B. Singh, "Cowpea, a multifunctional legume," in In Genomics of tropical crop plants, P. H. Moore and R. Min, Eds., pp. 227-257, Springer, New York, NY, USA, 2008.

[2] V. Sivakumar, V. A. Celine, D. Shrishail, P. Sanjeev, and M. Santosh Kumar, "Genetic Variability and Heritability Studies in Bush Cowpea (Vigna unguiculata(L.) Walp.)," Legume Genomics and Genetics, vol. 4, pp. 27-31, 2013.

[3] S. Wiggins, "Can the smallholder model deliver poverty reduction and food security for a rapidly growing population in Africa?" in Paper for the Expert Meeting on How to feed the World in 2050, Rome, 2009.

[4] S. Wiggins and K. Sharda, Looking back, peering forward": what has been learned from the food-price spike, 2007-2008, 2013.

[5] R. Bressani, "Nutritive value of cowpea," in Cowpea: Research, Production and Utilization, S. R. Singh and K. O. Rachie, Eds., John Wiley and Sons, New York, 1985.

[6] K. Mafakheri, M. R. Bihamta, A. R. Abbasi, and M. T. Moral, "Assessment of genetic diversity in cowpea (Vigna unguiculata
L.) germplasm using morphological and molecular characterisation," Cogent Food \& Agriculture, vol. 3:1, 2017.

[7] S. Sefa-Dedeh, E. O. Afoakwa, and E. Sakyi-Dawson, "Comparative Evaluation of Cowpea Varieties and their Performance in a Fermented Food Product," in A paper presented at the Annual Meeting of the Institute of Food Technologists, New Orleans, LA. Implications for breeding $W, 2011$.

[8] S. A. Tarawali, B. B. Singh, M. Peters, and S. F. Blade, "Cowpea haulms as fodder," in Advances in Cowpea Research, B. B. Singh, D. R. Mohan Raj, K. E. Dashiell, and L. E. N. Jackai, Eds., pp. 313-325, Co publication of International Institute of Tropical Agriculture and Japan International Research Center for Agricultural Science, Sayce, Devon, UK, 2000.

[9] F. A. Nkaa, O. W. Nwokeocha, and O. Ihuoma, "Effect of Phosphorus fertilizer on growth and yield of cowpea (Vigna unguiculata)," Journal of Pharmacy and Biological Sciences, vol. 9, no. 5, pp. 74-82, 2014.

[10] A. K. Belane and F. D. Dakora, "Measurement of N2 fixation in 30 cowpea (Vigna unguiculata L. Walp.) genotypes under field conditions in Ghana, using the $15 \mathrm{~N}$ natural abundance technique," Symbiosis, vol. 48, no. 1-3, pp. 47-56, 2009.

[11] J. B. Naab, S. M. B. Chimphango, and F. D. Dakora, "N2 fixation in cowpea plants grown in farmers' fields in the Upper West Region of Ghana, measured using $15 \mathrm{~N}$ natural abundance," Symbiosis, vol. 48, no. 1-3, pp. 37-46, 2009.

[12] E. M. Agbicodo, C. A. Fatokun, S. Muranaka, R. G. F. Visser, and C. G. Linden Van Der, "Breeding drought tolerant cowpea: Constraints, accomplishments, and future prospects," Euphytica, vol. 167, no. 3, pp. 353-370, 2009.

[13] F. A. Armah, J. O. Odoi, G. T. Yengoh, S. Obiri, D. O. Yawson, and E. K. A. Afrifa, "Food security and climate change in drought-sensitive savanna zones of Ghana," Springer Science + Business Media, vol. 16, no. 3, pp. 291-306, 2010.

[14] M. J. Mortimore, B. B. Singh, F. Harris, and S. F. Blake, "Cowpea in traditional cropping systems," in Advances in Cowpea Research, Co publication of International Institute of Tropical Agriculture and Japan International Research Center for Agricultural Science, 1997.

[15] P. N. Kauret, S. M. Shingnapure, V. N. Waghmare, and S. Sutar, "Genetic diversity analysis of some exotic, Indain and Mutant Brassiea sp. Throuth RAPD markers," African Journal of Biotechnology, vol. 9, pp. 3981-3987, 2009.

[16] J. Abadassi, "Cowpea (Vigna unguiculata (L.) Walp.) Agronomic Traits Needed in Tropical Zone," International Journal of Pure and Applied Bioscience, vol. 3, no. 4, pp. 158-165, 2015.

[17] A. O. Adeyanju and M. F. Ishiyaku, "Genetic Study of Earliness in Cowpea (Vigna unguiculata (L.) Walp) Under Screen House Condition," International Journal of Plant Breeding and Genetics, vol. 1, pp. 34-37, 2007.

[18] M. A. Ayo-Vaughan, O. J. Ariyo, I. O. Daniel, and C. O. Alake, "Diallel analysis of earliness in cowpea," in Proceedings of the African crop Science Conference Proceedings, vol. 10, pp. 521-524, 2011.

[19] A. Pswarayi and B. S. Vivek, "Combining ability amongst CIMMYT's early maturing maize (Zea mays L.) germplasm under stress and non-stress conditions and identification of testers," Euphytica, vol. 162, no. 3, pp. 353-362, 2007.

[20] Y. H. Song, S. Ito, and T. Imaizumi, "Flowering time regulation: Photoperiod- and temperature-sensing in leaves," Trends in Plant Science, vol. 18, no. 10, pp. 575-583, 2013.

[21] M. S. Alidu, R. Akromah, and I. D. K. Atokple, "Genetic Analysis of Vegetative-Stage Drought Tolerance in Cowpea," 
Greener Journal of Agricultural Sciences, vol. 3, no. 6, pp. 476491, 2013.

[22] W. Nicole, X. Shizhong, and J. Ehlers, "Estimating the BroadSense Heritability of Early Growth of Cowpea," International Journal of Plant Genomics, vol. 4, p. 2009, 2009.

[23] N. Akhshi, C. Kianoosh, A. Hadi, and N. F. Farhad, "eneration mean analysis to estimate genetic parameters for morphological traits in common bean (Phaseolus vulgaris L.)," Journal of Biodiversity and Environmental Sciences, vol. 3, pp. 254-257, 2014.

[24] CSIR-Savanna Agricultural Research Institute, "Meteorological station, 2015".

[25] R. W. Payne, D. A. Murray, S. A. Harding, D. B. Baird, and D. M. Soutar, Genstat for Windows (12 ${ }^{\text {th }}$ Edition) Introduction, VSN International, Hemel Hempstead, UK, 12th edition, 2009.

[26] S. Wright, "The Genetics of Qualitative Variability," in In Evolution and Genetics of Populations. Vol. I. Genetic and Biometric Foundations, S. Wright, Ed., vol. I, University of Chicago Press, Chicago, USA, 1968.

[27] G. Acquaah, "Introduction to quantitative genetics," in In Principles of plant genetics and breeding, pp. 121-145, Blackwell Publishing, Malden, MA, USA, 2007.

[28] S. Fonseca and F. L. Paterson, "Hybrid vigour in seven diallel crosses in common winter wheat (Triticumae stivumL.)," Crop Science, vol. 8, pp. 85-88, 1968.

[29] B. B. Singh, O. O. Olufajo, M. F. Ishiyaku, R. A. Adeleke, H. A. Ajeigbe, and S. G. Mohammed, "Farmer preferences and legume intensification for low nutrient environments," Journal of Plant Registrations, vol. 1, pp. 48-49, 2007.

[30] S. O. Bennet-Lartey and K. Ofori, "Variability in some quantitative characters of cowpea (Vigna unguiculata(L.) Walp) landraces in Ghana," Ghana Journal of Agricultural Science, vol. 33, pp. 165-170, 2000.

[31] O. M. Egbe, S. E. Alibo, and I. Nwueze, "Evaluation of some extra-early- and early-maturing cowpea varieties for intercropping with maize in southern Guinea Savanna of Nigeria," Agriculture and Biology Journal of North America, vol. 1, no. 5, pp. 845-858, 2010.

[32] K. N. Futuless and I. D. Bake, "Evaluation of yield and yield attributes of some Cowpea (Vigna unguiculata (L) Walp) Varieties In Northern Guinea Savanna," Journal of American Science, vol. 6, no. 8, pp. 508-511, 2010.

[33] A. S. Gerrano, P. O. Adebola, W. S. Jansen Van Rensburg, and S. M. Laurie, "Genetic variability in cowpea (Vigna unguiculata (L.) Walp.) genotypes," South African Journal of Plant and Soil, vol. 32, no. 3, pp. 165-174, 2015.

[34] K. Alphonsu, J. A. Belane, and F. D. Dakora, "Assessment of $\mathrm{N}_{2}$ fixation in 32 cowpea (Vigna unguiculata(L.) Walp) genotypes grown in the field at Taung in South Africa, using $15 \mathrm{~N}$ natural abundance," African Journal of Biotechnology, vol. 10, no. 55, pp. 11450-11458, 2011.

[35] M. N. Barakat, "Estimation of genetic parameters for in vitro traits in wheat immature embryo cultures involving high $\mathrm{X}$ low regeneration capacity genotypes," Euphytica, vol. 87, no. 2, pp. 119-125, 1996.

[36] B. C. Oyiga and M. I. Uguru, "Genetic Variation and Contributions of Some Floral Traits to Pod Yield in Bambara Groundnut (Vigna subterranea $(\mathrm{L})$. Verdc) under Two Cropping Seasons in the Derived Savanna of the South-East Nigeria," International Journal of Plant Breeding, vol. 5, pp. 58-63, 2011.
[37] L. C. R. Hugo, S. B. Leonardo, and C. A. Fernandes, "Genetic parameters of earliness and plant architecture traits suitable for mechanical harvesting of cowpea (Vigna unguiculata)," Australian Journal of Crop Science, vol. 8, pp. 1232-1238, 2014.

[38] W. Manggoel, M. I. Uguru, O. N. Ndam, and M. A. Dasbak, "Genetic variability, correlation and path coefficient analysis of some yield components of ten cowpea (Vigna unguiculata(L.) Walp)," Journal of Plant Breeding and Crop Science, vol. 4, pp. 80-86, 2012.

[39] J. N. Warner, "A method for estimating heritability", Agronomy Journal, vol. 44, pp. 427-430, 1952.

[40] M. F. Ishiyaku, B. B. Singh, and P. Q. Craufurd, "Inheritance of time to flowering in cowpea (Vigna unguiculata (L.) Walp.)," Euphytica, vol. 142, no. 3, pp. 291-300, 2005.

[41] R. Soehendi and P. Srinives, "Significance of Heterosis and Heterobeltiosis in an $\mathrm{F}_{1}$ hybrid of mungbean (vigna radiate(L.) wilczek) for hybrid seed production, Sabrao," Sabrao Journal of Breeding and Genetics, vol. 37, pp. 97-105, 2005.

[42] O. B. Bell and J. O. Odunayo, "Gene action, heterosis, correlation and regression estimates in developing hybrid cultivars in maize," Journal of Agricultural Research, vol. 48, no. 1, pp. 35-38, 2016.

[43] W. H. Brittingham, "The inheritance of date of pod maturity, pod length, seed shape and seed size in the southern pea, Vigna sinensis," Proceedings of the Society for Horticultural Science, vol. 51, pp. 281-288, 1950.

[44] C. K. Nakawuka and E. Adipala, "A path coefficient analysis of some yield component interactions in cowpea," African Crop Science Journal, vol. 7, no. 4, pp. 327-331, 1999.

[45] G. E. Nwofia, M. Nwanebu, and C. U. Agbo, "Variability and Inter-relationships between Yield and Associated Traits in Cowpea (Vigna unguiculata (L.) Walp as Influenced by Plant Populations," World Journal of Agricultural Sciences, vol. 8, no. 4, pp. 396-402, 2012. 


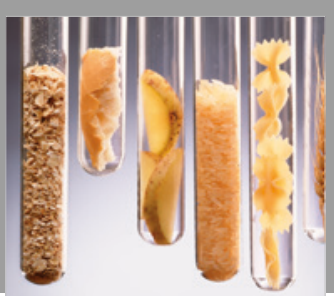

International Journal of Food Science

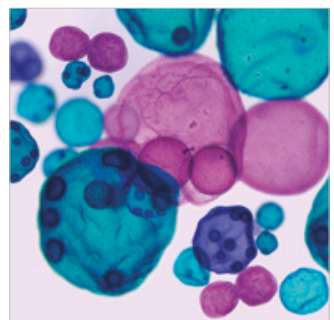

International Journal of Microbiology
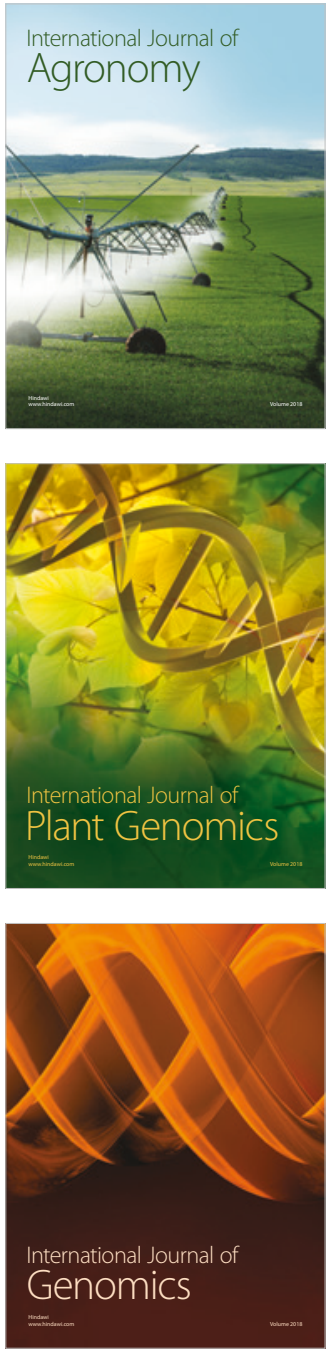

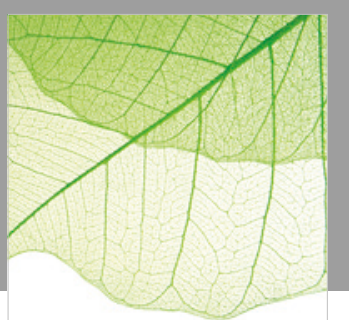

Journal of Botany
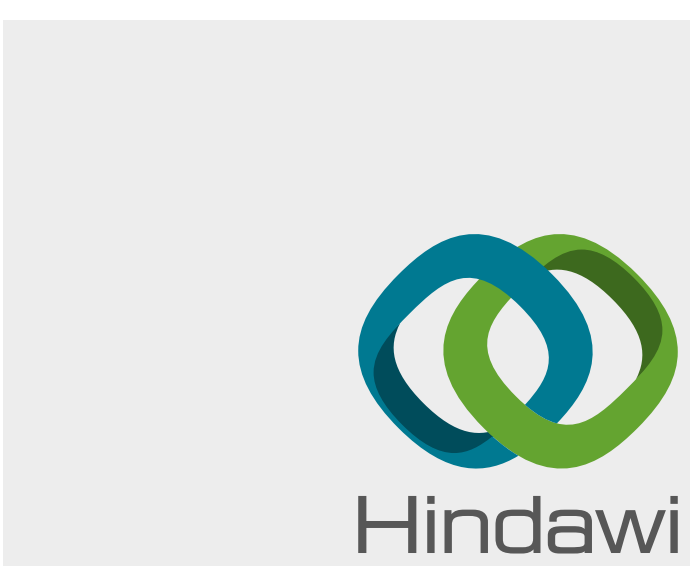

Submit your manuscripts at

www.hindawi.com
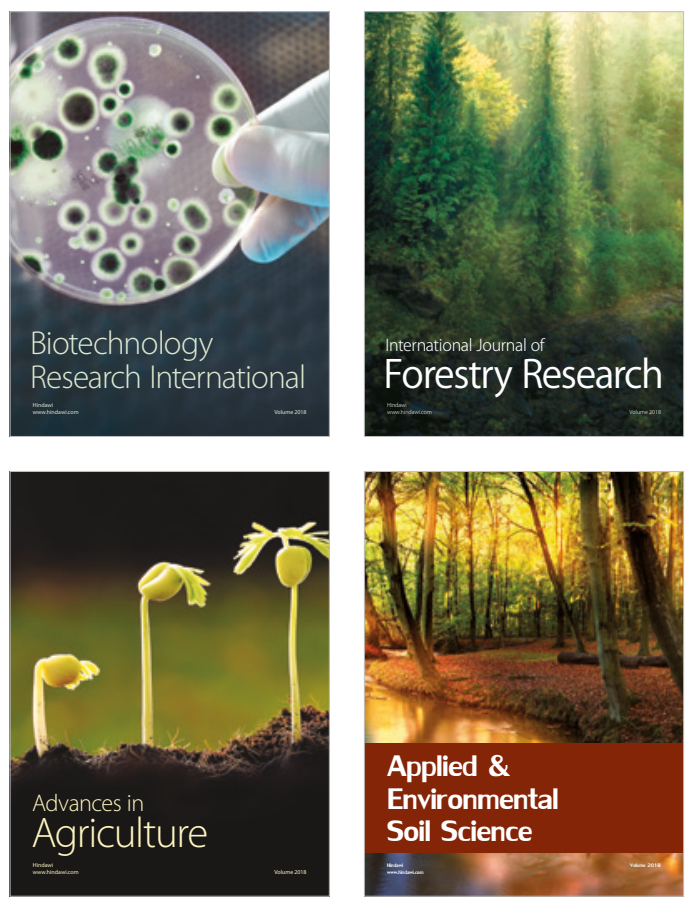

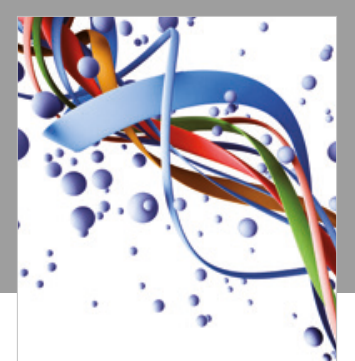

Scientifica

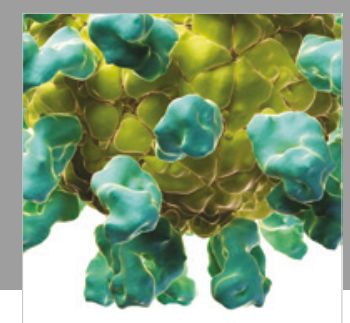

Veterinary Medicine International

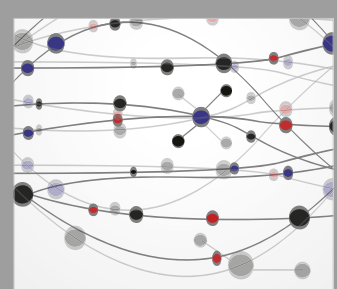

The Scientific World Journal
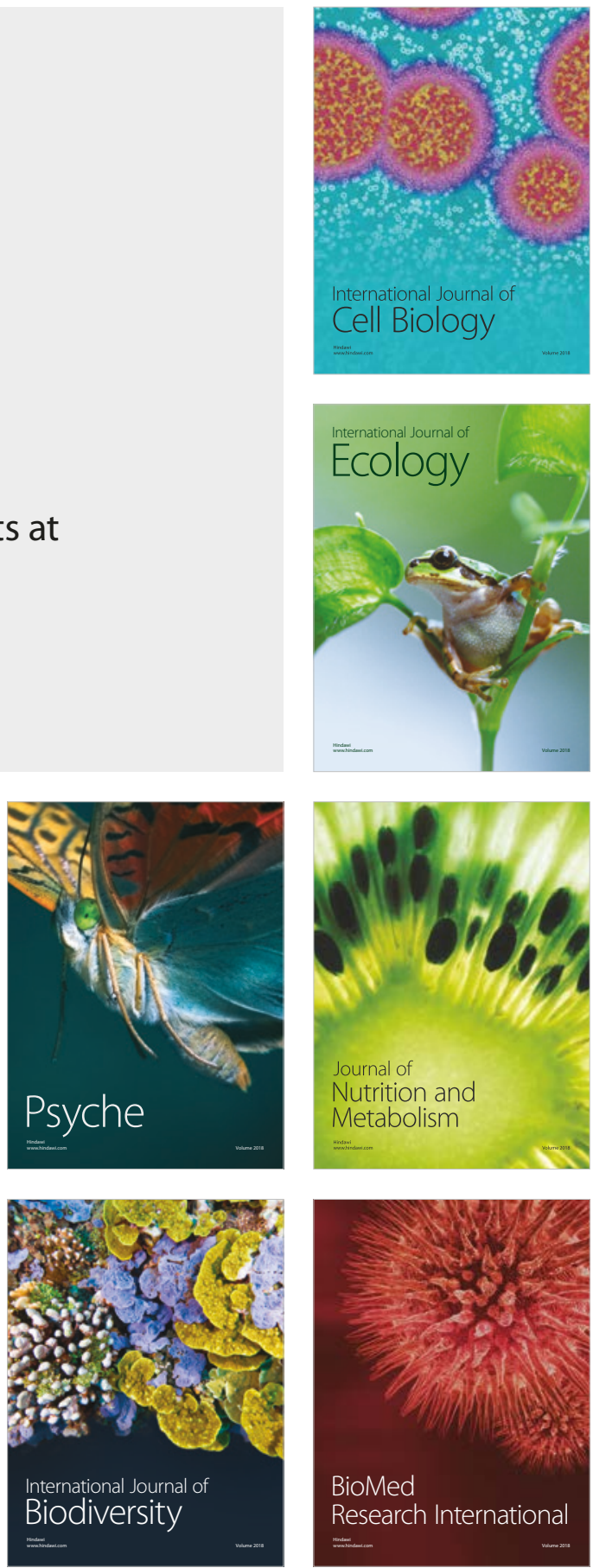